\title{
Pilot Study of Flow and Meaningfulness as Psychological Learning Concepts in Patient Education: A Short Report
}

\author{
Sara Nicic ${ }^{1}$, Karina Nørby², Clea Bruun Johansen1, Ingrid Willaing1 \\ ${ }^{1}$ Steno Health Promotion Center, Steno Diabetes Center, Gentofte, Denmark \\ ${ }^{2}$ Municipal of Faxe, Faxe, Denmark \\ Email: srnc@steno.dk
}

Received 14 February 2014; revised 12 March 2014; accepted 11 April 2014

Copyright (C) 2014 by authors and Scientific Research Publishing Inc.

This work is licensed under the Creative Commons Attribution International License (CC BY). http://creativecommons.org/licenses/by/4.0/

(c) (i) Open Access

\begin{abstract}
Background: The aim of this pilot study was to explore patient experiences of meaningfulness and flow related to group based patient education in type 2 diabetes. Meaningfulness and flow are underexposed as psychological learning concepts in patient education, and the ambition of this study was to investigate the applicability of these concepts of positive psychological theory in a patient education setting. Methods: This pilot study combines participating observation of group based patient education and 8 qualitative interviews with 4 patients with type 2 diabetes. Meaning condensation was used as an analytical tool to identify themes. Preliminary results: When the teaching activities were experienced as engaging for the patients and/or when they stimulated flow, it was due to 1) the perceived relevance of the activities, 2) the acquisition of new knowledge and 3) the feeling of importance in relation to life with diabetes. However, patients only reported a few activities and situations that indicated flow states. A sense of meaningfulness occurred when the patients experienced a sense of community and connectedness, which they obtained from being together with the other patients in the patient education setting. Patients experienced that there was a clear, comprehensive and structured plan for the education programme which was followed. This stimulated their experiences of meaningfulness and flow.
\end{abstract}

\section{Keywords}

Positive Psychology, Flow, Meaningfulness, Patient Education, Diabetes

*Corresponding author. 


\section{Introduction}

Across the world an increasing number of people are today living with chronic or long-term diseases (Newman, Steed, \& Mulligan, 2004; World Health Organisation, 2010), and diabetes is one of the most common chronic diseases in the western world (Celano, Beale, Moore, Wexler, \& Huffman, 2013). Patient education is a specific prevention initiative focusing on promoting health in people with chronic and long-term diseases, e.g. diabetes, by mobilising their resources. Patient education aims at encouraging people with a chronic disease to engage, participate and take ownership in the management of their disease (Norris, Engelgau, \& Narayan, 2001; Gary, Genkinger, Guallar, Peyrot, \& Brancati, 2004). However, effects of patient education are largely undetermined and the focus on specific learning concepts and processes is greatly underexposed (Ellis, Speroff, Dittus, Brown, Pichert, \& Elasy, 2004; Cooper, Booth, Fear, \& Gill, 2001; Davies, Heller, Skinner, Campbell, Carey, Cradock et al., 2008; Khunti, Gray, Skinner, Carey, Realf, Dallosso et al., 2012; Schiøtz, Bøgelund, Almdal, \& Willaing, 2012). Patient education focusing on biomedical health behaviour has not improved diabetes outcomes significantly (Cooper, Booth, \& Gill, 2008). However, there is clear evidence that the positive psychology framework has an impact on the daily management and health outcomes of patients with diabetes (Yi-Frazier, Hilliard, Cochrane, \& Hood, 2012). This could beneficially be addressed in efforts to improve outcomes (Yi-Frazier, Hilliard, Cochrane, \& Hood, 2012).

\section{Aim of the Study}

Most of the literature on interventions using positive psychology and targeting patients with diabetes has focused on increasing self-efficacy and resilience (Celano, Beale, Moore, Wexler, \& Huffman, 2013). Little is known about flow and meaningfulness as positive psychological learning concepts in group based patient education. The aim of this pilot study was to explore how, when and in what situations and activities flow and meaningfulness occurred in a groupbased patient education programme targeting patients with type 2 diabetes and focusing on everyday life with diabetes. The ambition of the pilot study was to investigate the applicability of these concepts of positive psychological theory in a patient education setting.

\section{Theoretical Framework}

\subsection{Flow}

Flow is defined as a subjective, mental state where the individual is completely engaged and focused to the point of forgetting time, fatigue and everything but the present activity (Csikszentmihalyi, Abuhamdeh, \& Nakamura, 2005; Csikszentmihalyi, 1996). The flow state indicates that thoughts, feelings and intentions are in harmony and that attention is focused outwards on the activity itself (Nakamura \& Csikszentmihalyi, 2002). The sense of time becomes distorted as time often passes quickly for the engaged individual during flow (Csikszentmihalyi, 1996; Csikszentmihalyi \& Lefevre, 1989; Csikszentmihalyi \& Csikszentmihalyi, 1988). Flow is associated with highly engaging activities and situations (Csikszentmihalyi, 1997). According to neuropsychological research (Kensiger, 2004) activities that implicate flow tend to be remembered as these activities are associated with positive emotions and evaluated very positively afterwards. Flow is important as a psychological learning concept as the experience of flow, according to Csikszentmihalyi, is a powerful motivating force (Csikszentmihalyi, Abuhamdeh, \& Nakamura, 2005; Csikszentmihalyi \& Csikszentmihalyi, 1988). Furthermore, activities that are flow generating are perceived as very meaningful, stimulating the memory and associated with positive emotions (Gläser-Zikuda \& Mayring, 2005). Flow experiences are relatively rare in adult life, but flow can be stimulated in, e.g. a pedagogical setting by providing optimal environmental preconditions (Csikszentmihalyi, Abuhamdeh, \& Nakamura, 2005; Csikszentmihalyi, 1996; Csikszentmihalyi \& Lefevre, 1989; Csikszentmihalyi \& Csikszentmihalyi, 1988). The flow stimulating preconditions are a clear set of goals that provide direction, a balance between personal perception of perceived skills and perceived challenges, a clear and immediate feedback and an environmental setting where it is possible to focus the attention and get absorbed in an activity. In a pedagogical setting this implies undisturbed periods of time and with no or few distractions (Csikszentmihalyi, 2007; Csikszentmihalyi, 2008).

\subsection{Antonovskys Meaningfulness}

While the concept of flow refers to the specific pedagogical situation, the theory of Sense of Coherence refers to 
the general feeling of confidence in the individual when meeting demands and challenges across internal and external environments (Yi-Frazier, Hilliard, Cochrane, \& Hood, 2012). Antonovskys Sense of Coherence (SOC) theory is constituted by three components: comprehensibility, manageability and meaningfulness (Antonovsky, 1979; Antonovsky, 1987). In this pilot study sense of meaningfulness is also considered an important positive psychological learning concept, as meaningfulness is closely connected to flow. The flow experience can be considered a predecessor as well as an outcome of meaningfulness (Delle Fave, 2009). Moreover meaningfulness is an important motivating factor, according to Csikszentmihalyi, as adults need to experience learning activities as meaningful if they are to be actively involved and engaged (Csikszentmihalyi \& Csikszentmihalyi, 1988). According to Antonovsky one is inclined to engage in and get emotionally involved in situations perceived as meaningful (Antonovsky, 1987). Sense of meaningfulness is constituted through involvement and participation in the challenges and activities that life presents to the individual. In contrast non-involvement and non-participation decreases the sense of meaningfulness (Antonovsky, 1987; Baumeister, 2002). A person with a strong sense of meaningfulness meets life challenges with determination to find meaning in them and to overcome them (Antonovsky, 1998).

\section{Method}

\subsection{Setting}

The group based patient education took place in a specialist diabetes clinic in Denmark and included patients with type 2 diabetes. Patients were referred to the diabetes clinic by their general practitioner due to complications to their diabetes. The treatment at the clinic included, among other things, a two day patient education programme of twelve hours in total with one month between the two days of education. The educators were a diabetes specialist, a podiatrist, two diabetes nursesand a dietitian. Their didactic approach was mainly traditional with a focus on individual learning processes and the transfer of knowledge from the educator to the patient. To a limited extent interactive teaching and exchange of experiences in the group of patients was also part of the patient education programme.

\subsection{Ethics}

The pilot study was approved by the Danish Data Protection Agency and the patients gave informed consent prior to the study.

\subsection{Participating Observation}

Participating observation was conducted the two full days of the programme. A researcher (KN) was present through the entire programme and participated as an observer in all lessons. Field notes were written during the full two days. Focus of the observations was the preconditions of flow (Csikszentmihalyi, Abuhamdeh, \& Nakamura, 2005; Csikszentmihalyi \& Lefevre, 1989; Csikszentmihalyi \& Csikszentmihalyi, 1988).

\subsection{Interviews}

\subsubsection{Recruitment}

Patients were recruited at the first day of the patient education programme. Four patients volunteered and agreed to participate in two in-depth interviews; one after the first day of the programme and one at the end of the second day. Altogether 8 interviews were conducted. The patients were two women aged 64 and 66 and two men at the age of 66 and 57. There was a considerable variation in the medical diabetes history of the patients. The criteria for selection were that they were patients and not relatives (who were also invited to attend the education programme), and that both genders were represented. Six interviews were conducted in the homes of the patients while one patient chose to be interviewed at the diabetes clinic. The duration of the interviews ranged from 25 minutes to one hour. All interviews were recorded and transcribed verbatim.

\subsubsection{Analysis}

Transcripts from the interviews and field notes from the participating observation were read and analysed in the framework of meaning condensation and then organised in central themes. Themes from each interview were 
compared and variations and similarities were identified (Kvale, 1996). Themes were structured in three parts (Figure 1). The focus was particularly on patient experiences of flow and meaningfulness.

\section{Preliminary Results of the Pilot Study}

\subsection{Experiences of Meaningfulness and Flow in the Patient Education}

Teaching activities and the information presented from the education program were recalled when directed precisely at what patients found relevant and meaningful according to their specific life situations with diabetes and in relation to their lives in general. When the teaching activities were experienced as engaging and/or when they stimulated flow, it was due to 1) the perceived relevance of the activities, 2) the acquisition of new knowledge and 3) the feeling of importance in relation to life with diabetes. However, patients only reported a few activities and situations that indicated flow states. A sense of meaningfulness occurred when the patients experienced a sense of community and connectedness, which they obtained from being together with the other patients in the patient education setting.

\subsection{Patient Education as a Framework for the Experience of Meaningfulness and Flow}

Patients experienced that there was a clear, comprehensive and structured plan for the education programme which was followed. This stimulated their experiences of meaningfulness and flow. The framework of the patient education programme was mainly perceived as understandable and manageable by the patients. This corresponds to the necessary pre-conditions for the stimulation of flow and underlines the importance of clear goals in the activities presented to the patients.

Established on the field notes from the participating observation the teaching activity defined as "the round" was registered and evaluated as a highly meaningful activity. Here patients individually elaborated their personal goals and gave each other feedback. In this specific learning activity meaningfulness was generated on basis of the patient experience of a high degree of participation and in the recognizability of the other patients' stories about their life situation.

\subsection{The Patient Education as a Basis for New Life Planning}

Patients evaluated various diabetes teaching materials as very important and meaningful in relation to their everyday lives. The materials were perceived as manageable and action oriented tools to deal with ongoing challenges with diabetes. Furthermore, the materials turned abstract knowledge into realistic methods, which promoted the feeling of comprehensibility.

\section{Further Research}

There is a need for further research in a larger scale to confirm the preliminary findings of this pilot study. Moreover, there is a need to identify innovative treatment modalities that can further help optimizing outcomes in diabetes (Celano, Beale, Moore, Wexler, \& Huffman, 2013). At present a larger study is being conducted with flow and meaningfulness as the theoretical framework. In that study health care professionals will be trying to integrate the pre-conditions of flow and the findings of this pilot study in the patient education setting. The aim of the larger study is to investigate whether a foundation of dialogue and the application of practical learning in patient education more easily can generate flow and meaningfulness compared to a traditional learning approach with individual learning processes and transfer of knowledge from the educator to the patient. Dialogue tools and a concept developed for group based dietary advice to people with Pakistani origin and type 2 diabetes

1) Analysis of interview data
(8 interviews)
Experiences of flow and meaningfulness
in the patient education.

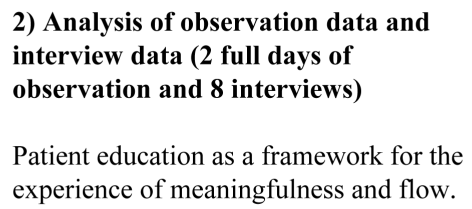

Figure 1. The three themes and the data used. 
(project DEEP) will be used in different patient education settings. The study will be conducted in collaboration with three public health care centres and a specialised diabetes clinic in Denmark.

\section{References}

Antonovsky, A. (1979). Health, Stress, and Coping. London: Jossey-Bass Publishers.

Antonovsky, A. (1987). Unraveling the Mystery of Health: How People Manage Stress and Stay Well. San Francisco, CA: Jossey-Bass Publishers.

Antonovsky, A. (1998). Ch.1: The Sense of Coherence: An Historical and Future Perspective. In Stress, Coping, and Health in Families: Sense of Coherence and Resiliency (pp.3-20). London: SAGE Publications.

Baumeister, R. F., \& Vohs, K. D. (2002). The Pursuit of Meaningfulness in Life. In C. R. Snyder, \& S. J. Lopez (Eds.), Handbook of Positive Psychology (pp. 608-618). Oxford: Oxford University Press.

Celano, C. M., Beale, E. E., Moore, S. V., Wexler, D. J., \& Huffmann, J. C. (2013). Positive Psychological Characteristics in Diabetes: A Review. Current Diabetes Report, 13, 917-929.

Cooper, H., Booth, K., Fear, S., \& Gill, G. (2008). A Trial of Empowerment-Based Education in Type 2 Diabetes-Global Rather than Glycaemic Benefits. Diabetes Research and Clinical Practice, 82, 165-171.

http://dx.doi.org/10.1016/j.diabres.2008.07.013

Csikszentmihaly, M., \& Csikszentmihalyi, I. (1988). Optimal Experience: Psychological Studies of Flow in Consciousness. Cambridge: Cambridge University Press. http://dx.doi.org/10.1017/CBO9780511621956

Csikszentmihalyi, M., \& LeFevre, J. (1989). Optimal Experience in Work and Leisure. Journal of Personality and Social Psychology, 56, 815-822. http://dx.doi.org/10.1037/0022-3514.56.5.815

Csikszentmihalyi, M. (1996). Creativity: Flow and the Psychology of Discovery and Invention. New York: Harper Collins Publishers.

Csikszentmihalyi, M. (1997). Finding Flow: The Psychology of Engagement with Everyday Life. New York: Basic Books.

Csikszentmihalyi, M., Abuhamdeh, S., \& Nakamura, J. (2005). Flow. In Handbook of Competence and Motivation (pp. 598608). New York: The Guilford Press.

Csikszentmihalyi, M. (2007). The Psychology of Engagement with Everyday Life. Virum: Dansk Psykologisk Forlag.

Csikszentmihalyi, M. (2008). The Psychology of Optimal Experience. Virum: Dansk Psykologisk Forlag.

Davies, M. J., Heller, S., Skinner, T. C., Campbell, M. J., Carey, M. E., Cradock, S., Dallosso, H. M., Daly, H., Doherty, Y., Eaton, S., Fox, C., Oliver, L., Rantell, K., Rayman, G., \& Khunti, K. (2008). Effectiveness of the Diabetes Education and Self-Management for Ongoing and Newly Diagnosed (DESMOND) Programme for People with Newly Diagnosed Type 2 Diabetes: Cluster Randomised Controlled Trial. British Medical Journal, 336, 491-495. http://dx.doi.org/10.1136/bmj.39474.922025.BE

Delle Fave, A. (2009). Optimal Experience and Meaning: Which Relationship? Psychological Topics, 18, 285-302.

Ellis, S. E., Speroff, T., Dittus, R. S., Brown, A., Pichert, J. W., \& Elasy, T. A. (2004). Diabetes Patient Education: A Meta-Analysis and Meta-Regression. Patient Education and Counselling, 52, 97-105. http://dx.doi.org/10.1016/S0738-3991(03)00016-8

Gary, T. L., Genkinger, J. M., Guallar, E., Peyrot, M., \& Brancati, F. (2004). Meta-Analysis of Randomized Educational and Behavioral Interventions in Type 2 Diabetes. Diabetes Educator, 29, 488-501. http://dx.doi.org/10.1177/014572170302900313

Gläser-Zikuda, M., \& Mayring, P. (2005). Enchancing Enjoyment in Learning at School. In F. Pons, D. Hancock, L. Lafortune, \& P. Doudin (Eds.), Emotions in Learning (pp. 101-119). Aalborg: Aalborg Universitetsforlag.

Kensiger, E. A. (2004). Remembering Emotional Experiences: The Contribution of Valence and Arousal. Reviews in the Neurosciences, 15, 241-252.

Khunti, K., Gray, L. J., Skinner, T., Carey, M. E., Realf, K., Dallosso, H., Fisher, H., Campbell, M., Heller, S., \& Davies, M. J. (2012). Effectiveness of a Diabetes Education and Self-Management Programme (DESMOND) for People with Newly Diagnosed Type 2 Diabetes Mellitus: Three Year Follow-Up of a Cluster Randomised Controlled Trial in Primary Care. British Medical Journal, 344, Article ID: e2333. http://dx.doi.org/10.1136/bmj.e2333

Kvale, S. (1996). Ch. 11: Methods of Analysis. In Interviews-An introduction to Qualitative Research Interviewing (pp. 193-199). California: Sage Publications.

Nakamura, J., \& Csikszentmihalyi, M. (2002). The Concept of Flow. In C. Snyder, \& S. Lopez (Eds.), Handbook of Positive Psychology (pp. 89-105). New York: University Press.

Newman, S., Steed, L., \& Mulligan, K. (2004). Self-Management Interventions for Chronic Illness. The Lancet, 364, 
1523-1537. http://dx.doi.org/10.1016/S0140-6736(04)17277-2

Norris, S., Engelgau, M. M., \& Narayan, K. M. V. (2001). Effectiveness of Self-Management Training in Type 2 Diabetes. Diabetes Care, 24, 561-587. http://dx.doi.org/10.2337/diacare.24.3.561

Schiøtz, M., Bøgelund, M., Almdal, T., \& Willaing, I. (2012). Discrete Choice as a Method for Exploring Education Preferences in a Danish Population of Patients with Type 2 Diabetes. Patient Education and Counselling, 87, 217-225. http://dx.doi.org/10.1016/j.pec.2011.09.003

Yi-Frazier, J. P., Hilliard, M., Cochrane, K., \& Hood, K. K. (2012). The Impact of Positive Psychology on Diabetes Outcomes: A Review. Psychology, 3, 1116-1124. http://dx.doi.org/10.4236/psych.2012.312A165

World Health Organization (2010). Global Status Report on Noncommunicable Diseases 2010: Description of the Global Burden of NCD's, Their Risk Factors and Determinants. Geneva: World Health Organization. 